\title{
EFFICACY OF VARIOUS ROUTES OF DEXAMETHASONE ADMINISTRATION ON POST-OPERATIVE COMPLICATIONS FOLLOWING IMPACTED MANDIBULAR THIRD MOLAR SURGERIES, COMPARATIVE CLINICAL STUDY
}

\author{
Nermine Ramadan*
}

\begin{abstract}
Introduction: Corticosteroids are considered anti-inflammatory which considered the essential roles, as well as it reduces edema.

Aim: To compare the efficacy of dexamethasone injection submucosally, intra-masseteric and intra-muscular on post-operative swelling, mouth opening and pain following removal of mandibular impacted third molars. Type of Study: prospective randomized comparative clinical study.
\end{abstract}

Methods: The current study included forty-five patients with impacted mandibular third molars were selected to underwent surgical removal of mandibular third molars. Group I, comprised of fifteen patients who received pre-operative sub-mucosal $8 \mathrm{mg}$ dexamethasone injection, Group II, comprised of fifteen patients who received pre-operative Intra-masseteric $8 \mathrm{mg}$ dexamethasone injection and Group III, taking intramuscular dexamethasone injection, Postoperative assessment included: mouth opening, swelling as well as pain at the following intervals; $1^{\text {st }}, 3^{\text {rd }}$ and $7^{\text {th }}$ day post-operative.

Results: our study showed no statistically significant difference between mean MMO as well as VAS in Group I and II; both showed statistically significant higher mean MMO and VAS than Group III. Significant reduction in pain and swelling in both sub-mucosal, intra-masseteric and intramuscular but a greater immediate effect on trismus was seen in sub-mucosal and intramasseteric routes

Conclusion: preoperative administration of dexamethasone has greater post-operative effects. Dexamethasone injected preoperatively was safe and simple effective method to reduce postoperative complications such pain, swelling and trismus.

KEYWORDS: corticosteroid, dexamethasone, post-surgery swelling, third molar extraction

* Oral Surgery Department; Faculty of Dentistry; October 6 University; Giza , Egypt 


\section{INTRODUCTION}

Surgical trauma in oral cavity always causes tissue injury characterized by hyperemia, vasodilatation, increased capillary permeability with liquid accumulation due to increased osmotic pressure in capillaries in interstitial space. ${ }^{(1)}$ Edema is expression of exudates or transudation including hyperemia, vasodilatation however superimposition of infection is responsible for exudates. In the initial phase corticosteroids acts to suppress vasoactive substances production such as leukoterins and prostaglandins which in turn reduces fluid transudation as well as edema. ${ }^{(2)}$

Sequelae of postoperative complications such as pain, trismus and swelling depends upon various factors such as patients related factors and surgical procedures, varying physiological inflammatory response, degree of tissue trauma and extent of bone manipulation. ${ }^{(3)}$ In order to reduce these sequelae, different treatment modalities have been used such as non-steroidal anti-inflammatory drugs (NSAIDs) which can be in combination with opioids or steroids ${ }^{(4 ; 5)}$

\section{MATERIALS AND METHODS}

Permissions and approval were obtained from Research Ethics Committee for the study (No. RECO6U/8-2019)

Sample size: for ethical, scientific, economic reasons and for error probability, the total sample size for statistically significant reliable results was 45 patients. In the present study, gender factor was the considered variable which could be the source of bias; then patients were randomly divided into three equal groups and stratification was done based on gender.

Study setting: the current study was set up in Oral Surgery Department, forty five patients with impacted mandibular third molars, class II position
B were selected to undergo surgical removal of mandibular third molars. Group I, comprised of fifteen patients who received pre-operative submucosal $8 \mathrm{mg}$ dexamethasone injection, Group II, comprised of fifteen patients who received preoperative Intra-masseteric $8 \mathrm{mg}$ dexamethasone injection, Group III, comprised of fifteen patients who received intramuscular dexamethasone injection. Postoperative assessment included: mouth opening, swelling as well as pain at the following intervals; $1^{\text {st }}, 3^{\text {rd }}$ and $7^{\text {th }}$ day post-operative.

Study design: this was a prospective randomized comparative clinical study with a duration of 2 years. All the procedures were performed by the same surgeon.

Statistical tool used: one-way analysis of variance (ANOVA) $(\mathrm{P}<0.001$ taken as significant) was used for statistical analysis.

\section{Inclusion criteria:}

- Patients in the age group from 18 to 40 years.

- Patients were free from any systemic diseases.

- Impacted mandibular third molar class II position B.

\section{Exclusion criteria}

- Patients with existing active infections.

- Patients with systemic disorders

- Patients on steroids therapy

- Pregnant and lactating women.

Informed written consent was obtained from all the patients. They were then randomly divided into two groups.

- Group I: pre-operative SM injection

- Group II: pre-operative IM injection

- Group III: pre-operative Intra-Muscular injection 


\section{Surgical technique}

Initial pre-operative radiographic assessment was done for all patients. Aseptic protocol for surgical operations were followed. Inferior alveolar nerve block anesthesia was administered. Group I, was injected sub-mucosal dexamethasone, [Figure 1] Group II, Intra-masseteric dexamethasone was administered [Figure 2] Group III, Intra-muscular dexamethasone was injected pre-operatively.

Access to the impacted mandibular third molar was done through standard Ward's incision, followed by adequate bone removal then splitting of the tooth, finally tooth delivery was done. Irrigation of the sockets were done with $5 \%$ providone-

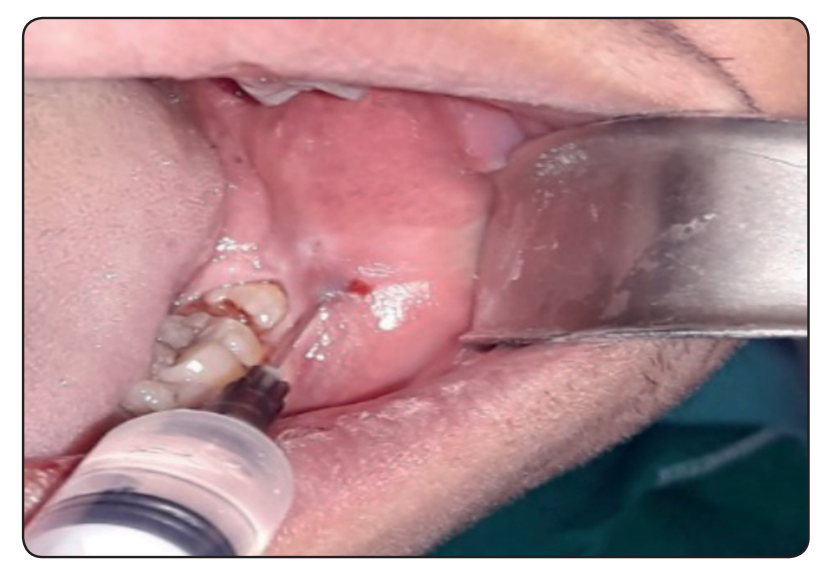

Fig. (1): clinical photograph showing submucosal dexamethasone injection in group I

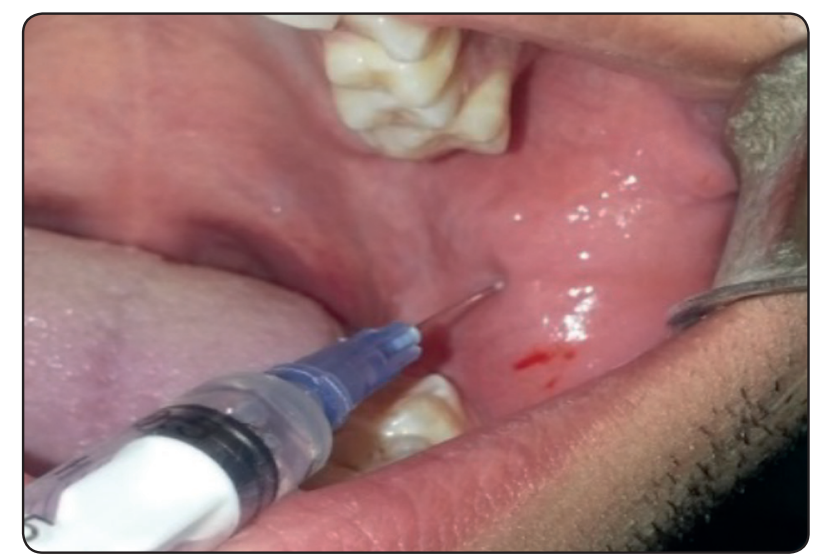

Fig. (2): clinical photograph showing intramasseteric dexamethasone injection in group II iodine solution diluted with normal saline. The flap was sutured back with 3-0 silk sutures using two interrupted sutures.

Post-operative instructions were given to patients including intermittent ice pack application for the next 6 hours. Antibiotic was prescribed (Amoxicillin $500 \mathrm{mg}$ thrice daily/ 5 days) analgesics (paracetamol $500 \mathrm{mg}$ thrice a day/ 3 days).

Sutures removal was done on the $7^{\text {th }}$ postoperative day if the healing was deemed to be satisfactory.

The following were assessed:

- Swelling: evaluated by a modification of tape measuring method described by SchultzeMosgau et al. ${ }^{(6)}$

- Trismus: measured as the maximum interincisal opening

- Pain: were evaluated using a Visual Analogue Scale (VAS)

\section{RESULTS}

Shapiro-Wilk and Kolmogorov-Smirnov tests; these are tests used for normality that were used for exploring numerical data for normality through checking data distribution. Non-parametric data were showed as median and range values. For parametric data, one-way ANOVA test was used to compare between mean age values in the two groups. Repeated measures ANOVA test was used to compare between mean MMO and edema measurement values in both groups as well as to study the changes by time within each group. When ANOVA test was significant, the Bonferroni's posthoc test was used comparison pair-wise. For nonparametric data, Kruskal-Wallis test was used to compare between both groups. Friedman's test was used to study the changes by time within each group. Dunn's test was used for pair-wise comparisons. 
Qualitative data were presented as frequencies and percentages. In order to compare between both groups, Chi-square test was used.

All patients were followed up for the following intervals; $1^{\text {st }}, 3^{\text {rd }}$ and $7^{\text {th }}$ days post-operative. Swelling evaluation: by a modification of tape measuring method described by Schultze-Mosgau et al. ${ }^{(6)}$ Two measurements were made between three reference points: Tragus, pogonion, and the corner of the mouth [Figure 3,4]. Pain evaluation: Post-operative pain was evaluated using a visual analogue scale (VAS) that ranged from $0=$ "no pain" to $10=$ "the worse possible pain." Trismus evaluation: Measured as the difference in maximal mouth opening (taken as the distance between upper and lower central incisors) before and after operation.

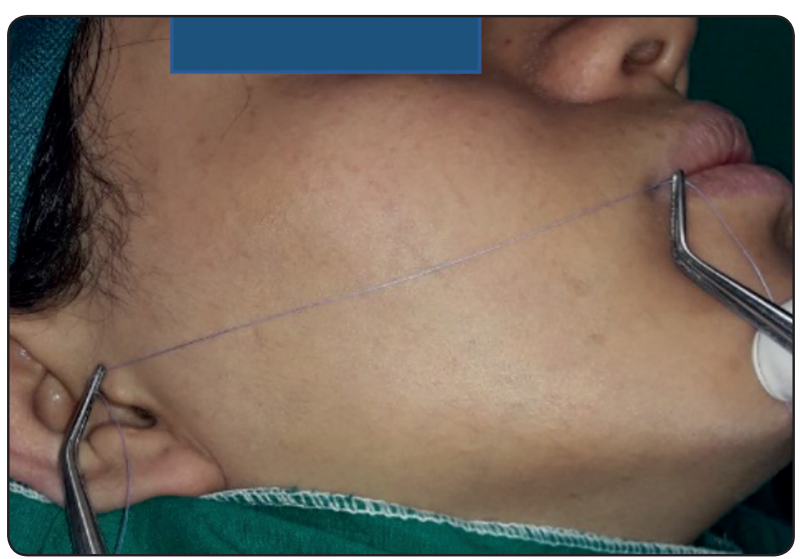

Fig. (3): pre-operative clinical photograph showing method of assessing swelling according to Schultze-Mosgau et al. ${ }^{6}$ from tragus to corner of mouth in group $\mathrm{I}=13.5 \mathrm{~cm}$

\section{Statistical Analysis:}

\section{Demographic data:}

There was no statistically significant difference between mean age values in both groups. There was also no statistically significant difference between gender distributions in both groups. (Table 1)

\section{I- Maximum Mouth Opening (MMO)}

As regards the changes by time in Group I, there was a statistically significant change in MMO by time $(P$-value $<0.001$, Effect size $=0.793)$. Pairwise comparisons between the time periods revealed that there was a statistically significant decrease in MMO after 1 day. From 1 day to 3 days as well as from 3 to 7 days, there was a statistically significant

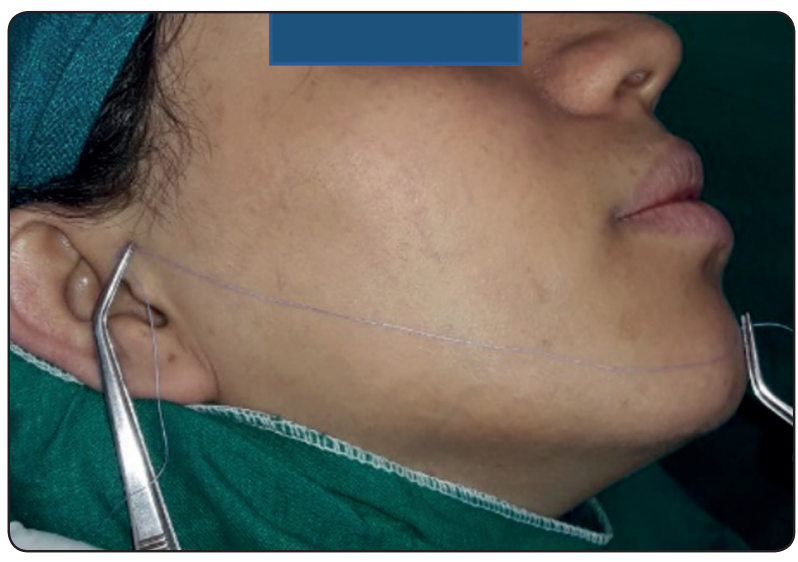

Fig. (4): pre-operative clinical photograph showing method of assessing swelling according to Schultze-Mosgau et al. ${ }^{6}$ from tragus to progonion in group $\mathrm{I}=18.5 \mathrm{~cm}$

TABLE (1): Mean, standard deviation (SD), frequencies (n), percentages and results of one-way ANOVA and Chi-square tests for comparisons of demographic data of both groups

\begin{tabular}{|c|c|c|c|c|}
\hline & $\begin{array}{c}\text { Group I } \\
(\mathbf{n = 1 5})\end{array}$ & $\begin{array}{c}\text { Group II } \\
(\mathbf{n}=\mathbf{1 5})\end{array}$ & $\begin{array}{c}\text { Group III } \\
(\mathbf{n}=\mathbf{1 5})\end{array}$ & P-value \\
\hline Age (Years) Mean (SD) & $27.6(4.8)$ & $29.8(5.2)$ & $28.5(5.9)$ & 0.530 \\
\hline Gender [n (\%)] & & & & \multirow{2}{*}{0.910} \\
\hline Male & $10(66.7)$ & $9(60)$ & $9(60)$ & \\
\hline Female & $5(33.3)$ & $6(40)$ & $6(40)$ & \\
\hline
\end{tabular}

\footnotetext{
*: Significant at $P \leq 0.05$
} 
increase in mean MMO. The mean MMO after 7 days showed non-statistically significant difference from pre-operative MMO measurement.

Similarly, in Group II, there was a statistically significant change in MMO by time ( $P$-value $<0.001$, Effect size $=0.772$ ). Pair-wise comparisons between the time periods revealed that there was a statistically significant decrease in MMO after 1 day. From 1 day to 3 days as well as from 3 to 7 days, there was a statistically significant increase in mean MMO. The mean MMO after 7 days showed non-statistically significant difference from preoperative MMO measurement; both groups showed statistically significantly higher mean MMO than Group III.

\section{II- Pain (VAS scores)}

As regards the changes by time in Group I, there was a statistically significant change in pain scores by time $(P$-value $<0.001$, Effect size $=0.970)$. Pairwise comparisons between the time periods revealed that there was a statistically significant decrease in pain scores from 1 day to 3 days as well as from 3 to 7 days. (Figure 5)

Similarly, in Group II, there was a statistically significant change in pain scores by time $(P$-value $<0.001$, Effect size $=0.851$ ). Pair-wise comparisons

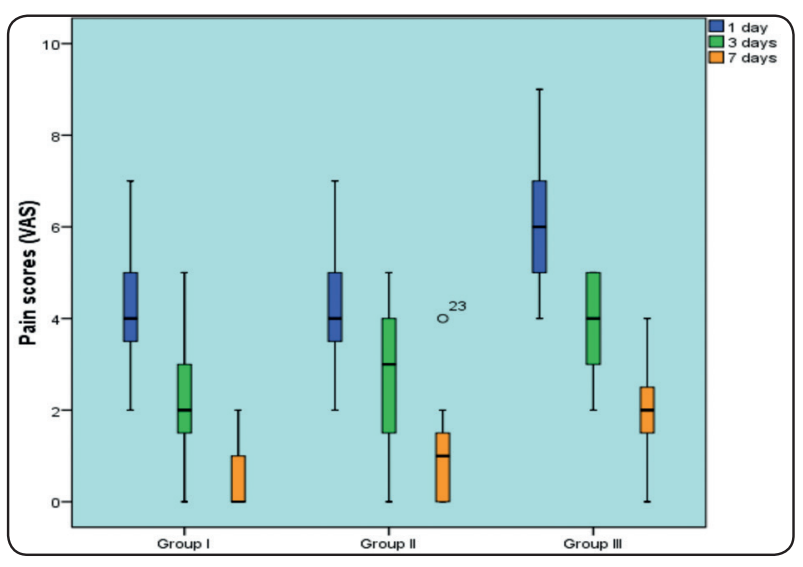

Fig. (5) Box plot representing median and range values for pain (VAS) scores in the three groups (Circle represents outlier) between the time periods revealed that there was a statistically significant decrease in pain scores from 1 day to 3 days as well as from 3 to 7 days. Both groups showed statistically significantly lower median pain scores than Group III.

\section{III-Swelling}

a- Tragus-corner of the mouth measurement:

As regards the changes by time in Group I, there was a statistically significant change in traguscorner of the mouth measurement by time ( $P$-value $<0.001$, Effect size $=0.492$ ). Pair-wise comparisons between the time periods revealed that there was a statistically significant increase in tragus-corner of the mouth measurement after 1 day, Both showed statistically significantly lower mean value than Group III.

From 1 day to 3 days, there was no statistically significant change in mean tragus-corner of the mouth measurements. From 3 to 7 days, there was a statistically significant decrease in mean tragus-corner of the mouth measurement. The mean tragus-corner of the mouth measurements after 7 days showed non-statistically significant difference from pre-operative tragus-corner of the mouth measurement, Both showed statistically significantly lower mean value than Group III.

As regards the changes by time in Group II, there was a statistically significant change in traguscorner of the mouth measurement by time ( $P$-value $<0.001$, Effect size $=0.692$ ). Pair-wise comparisons between the time periods revealed that there was a statistically significant increase in tragus-corner of the mouth measurement after 1 day. From 1 day to 3 days as well as 3 to 7 days, there was a statistically significant decrease in mean tragus-corner of the mouth measurements. The mean tragus-corner of the mouth measurements after 7 days showed non-statistically significant difference from preoperative tragus-corner of the mouth measurement. (Table 2) 
TABLE (2) Descriptive statistics and results of repeated measures ANOVA test for comparison between tragus-corner of the mouth measurements in the three groups as well as the changes by time within each group

\begin{tabular}{|c|c|c|c|c|c|}
\hline Time & $\begin{array}{l}\text { Group I } \\
(\mathbf{n}=15)\end{array}$ & $\begin{array}{l}\text { Group II } \\
(\mathbf{n}=15)\end{array}$ & $\begin{array}{l}\text { Group III } \\
\qquad(\mathbf{n}=15)\end{array}$ & $P$-value & $\begin{array}{c}\text { Effect size (Partial } \\
\text { Eta Squared) }\end{array}$ \\
\hline \multicolumn{4}{|l|}{ Pre-operative } & \multirow{3}{*}{0.304} & \multirow{3}{*}{0.055} \\
\hline Mean (SD) & $11(1.1)^{\mathrm{E}}$ & $10.8(1.2)^{\mathrm{F}}$ & $11.4(1.3)^{\mathrm{G}}$ & & \\
\hline $95 \% \mathrm{CI}$ & $10.3-11.6$ & $10.1-11.4$ & $10.8-12.1$ & & \\
\hline \multicolumn{4}{|l|}{1 day } & \multirow{3}{*}{$<0.001 *$} & \multirow{3}{*}{0.397} \\
\hline Mean (SD) & $12(1.1)^{\mathrm{BD}}$ & $12.3(1.1)^{\mathrm{BD}}$ & $14.1(1.3)^{\mathrm{AD}}$ & & \\
\hline $95 \% \mathrm{CI}$ & $11.4-12.6$ & $11.7-12.9$ & $13.5-14.7$ & & \\
\hline \multicolumn{4}{|l|}{3 days } & \multirow{3}{*}{$0.008^{*}$} & \multirow{3}{*}{0.207} \\
\hline Mean (SD) & $11.7(1.6)^{\mathrm{BD}}$ & $11.6(1.2)^{\mathrm{BE}}$ & $13.1(1.5)^{\mathrm{AE}}$ & & \\
\hline $95 \% \mathrm{CI}$ & $10.9-12.4$ & $10.8-12.3$ & $12.4-13.9$ & & \\
\hline \multicolumn{4}{|l|}{7 days } & \multirow{3}{*}{0.097} & \multirow{3}{*}{0.105} \\
\hline Mean (SD) & $11.1(1.3)^{\mathrm{E}}$ & $10.9(1.3)^{\mathrm{F}}$ & $11.9(1.4)^{\mathrm{F}}$ & & \\
\hline $95 \% \mathrm{CI}$ & $10.5-11.8$ & $10.3-11.6$ & $11.3-12.6$ & & \\
\hline$P$-value (Changes by time) & $<0.001 *$ & $<0.001 *$ & $<0.001 *$ & & \\
\hline Effect size (Partial Eta Squared) & 0.492 & 0.692 & 0.869 & & \\
\hline
\end{tabular}

*: Significant at $P \leq 0.05$

$A, B, C$ Superscripts in the same row indicate significant differences between groups

$D, E, F, G$ Superscripts in the same column indicate significant changes by time

\section{b- Tragus-Progonion measurement}

As regards the changes by time in Group I, there was a statistically significant change in tragus-Progonion measurement by time $(P$-value $<0.001$, Effect size $=0.549$ ). Pair-wise comparisons between the time periods revealed that there was a statistically significant increase in tragus-Progonion measurement after 1 day. From 1 day to 3 days as well as 3 to 7 days, there was a statistically significant decrease in mean tragus-Progonion measurement. The mean tragus-Progonion measurements after 7 days showed non-statistically significant difference from pre-operative tragus-Progonion measurement.
As regards the changes by time in Group II, there was a statistically significant change in tragus-Progonion measurement by time $(P$-value $<0.001$, Effect size $=0.710$ ). Pair-wise comparisons between the time periods revealed that there was a statistically significant increase in tragus-Progonion measurement after 1 day. From 1 day to 3 days as well as 3 to 7 days, there was a statistically significant decrease in mean tragus-Progonion measurements. The mean tragus-Progonion measurements after 7 days showed non-statistically significant difference from pre-operative tragus-Progonion measurement. (Table 3) 
TABLE (3) Descriptive statistics and results of repeated measures ANOVA test for comparison between tragus-Progonion measurements in the three groups as well as the changes by time within each group

\begin{tabular}{|c|c|c|c|c|c|}
\hline Time & $\begin{array}{l}\text { Group I } \\
(\mathbf{n}=\mathbf{1 5})\end{array}$ & $\begin{array}{l}\text { Group II } \\
(n=15)\end{array}$ & $\begin{array}{l}\text { Group III } \\
(\mathbf{n}=15)\end{array}$ & $P$-value & $\begin{array}{c}\text { Effect size (Partial } \\
\text { Eta Squared) }\end{array}$ \\
\hline Pre-operative & & & & \multirow{3}{*}{0.641} & \multirow{3}{*}{0.021} \\
\hline Mean (SD) & $14.8(1.5)^{\mathrm{F}}$ & $14.7(1.4)^{\mathrm{F}}$ & $15.1(1.3)^{\mathrm{G}}$ & & \\
\hline $95 \% \mathrm{CI}$ & $14-15.5$ & $13.9-15.4$ & $14.4-15.9$ & & \\
\hline \multicolumn{4}{|l|}{1 day } & \multirow{3}{*}{$0.002 *$} & \multirow{3}{*}{0.260} \\
\hline Mean (SD) & $16(1.7) \mathrm{BD}$ & $16.3(1.4)^{\mathrm{BD}}$ & $17.9(1.3) \mathrm{AD}$ & & \\
\hline $95 \% \mathrm{CI}$ & $15.2-16.7$ & $15.6-17.1$ & $17.2-18.7$ & & \\
\hline \multicolumn{4}{|l|}{3 days } & \multirow{3}{*}{$0.041 *$} & \multirow{3}{*}{0.141} \\
\hline Mean (SD) & $15.5(1.6)^{\mathrm{BE}}$ & $15.4(1.4)^{\mathrm{BE}}$ & $16.7(1.6)^{\mathrm{AE}}$ & & \\
\hline $95 \% \mathrm{CI}$ & $14.7-16.3$ & $14.6-16.2$ & $15.9-17.5$ & & \\
\hline \multicolumn{4}{|l|}{7 days } & \multirow{3}{*}{0.169} & \multirow{3}{*}{0.081} \\
\hline Mean (SD) & $14.9(1.6)^{\mathrm{F}}$ & $14.8(1.4)^{\mathrm{F}}$ & $15.7(1.5)^{\mathrm{F}}$ & & \\
\hline $95 \% \mathrm{CI}$ & $14.1-15.7$ & $14-15.6$ & $14.9-16.5$ & & \\
\hline$P$-value (Changes by time) & $<0.001 *$ & $<0.001 *$ & $<0.001 *$ & & \\
\hline Effect size (Partial Eta Squared) & 0.549 & 0.710 & 0.885 & & \\
\hline
\end{tabular}

*: Significant at $P \leq 0.05$

A,B,C Superscripts in the same row indicate significant differences between groups

$D, E, F, G$ Superscripts in the same column indicate significant changes by time

While in Group III, there was a statistically significant change in tragus-corner of the mouth measurement by time ( $P$-value $<0.001$, Effect size $=0.869)$. Pair-wise comparisons between the time periods revealed that there was a statistically significant increase in tragus-corner of the mouth measurement after 1 day. From 1 day to 3 days as well as 3 to 7 days, there was a statistically significant decrease in mean tragus-corner of the mouth measurements. However; the mean traguscorner of the mouth measurement after 7 day

\section{DISCUSSION}

The most commonly used forms of corticosteroids in dentoalveolar surgery include dexamethasone (oral), dexamethasone sodium phosphate (IV or IM), dexamethasone acetate (IM), methylprednisolone (oral), and methylprednisolone sodium succinate (IV/IM). The corticosteroid selected should have good biological activity and minimal mineralocorticoid effects. Dexamethasone meets these requirements, as it has no mineralocorticoid activity; the half-life is roughly 36 to 72 hours, highly selective, long-acting, synthetic 
corticosteroid, which has potent anti-inflammatory action. It exerts basic glucocorticoid action and was considered equipotent to betamethasone, 4 times than the triamcinolone and methyl prednisolone, 6 times than of prednisolone and 25 times more potent than hydrocortisone. ${ }^{(7)}$

Another study compared the two doses of dexamethasone, the 4 and $8 \mathrm{mg}$ and concluded that there is no difference on post-operative sequelae on increasing dexamethasone dose. Based on the following study we choose to use the $8 \mathrm{mg}$ dose of dexamethasone injection. ${ }^{(8)}$

Our study was in coincidence with other studies who proved that the dexamethasone administration pre-operatively offered a high comfort levels to patients. ${ }^{9,10,11)}$

Other authors in their studies reported significant reducing in facial edema following peri-operative sub-mucosal injection of $4 \mathrm{mg}$ of dexamethasone. ${ }^{(8,12)}$ Also, in other study it has been concluded that pre-operative single sub therapeutic dose of submucosal of dexamethasone will help in reducing the post-operative discomfort. ${ }^{(5)}$

This was in agreement to our study that concluded a statistically significant reduction in facial swelling after 1 day. However, from 1 day to 3 days as well as 3 to 7 days, there was a statistically significant increase in its measurement. On the other hand, the mean measurements after 7 days showed non-statistically significant difference from pre-operative measurement. Intramuscular group showed significant reduction of swelling after 7 th day.

Other study reported that preoperative administration of dexamethasone has greater postoperative effects. ${ }^{(13)}$ another study concluded that dexamethasone injected sub-mucosally was more efficient to manage post-operative discomfort resulted from pain and swelling following third molar removal. ${ }^{(14)}$ other authors compared the effect of sub-mucosal dexamethasone and found statistically significant reduction of swelling and trismus on 2 nd postoperative day when compared with control group. ${ }^{(15,16)}$ As well as a study done concluded that preoperative submucosal injection of steroids was safe and simple effective method to reduce postoperative complications such pain, swelling and trismus. ${ }^{(9,17)}$

This was in agreement to our study, the immediate effect on trismus as well as pain reduction following dexamethasone injection submucosally and intramasseteric on all follow up period post-operatively and swelling reduction on the $1^{\text {st }}$ day.

\section{CONCLUSION}

We concluded that local injection of $8 \mathrm{mg}$ dexamethasone through intra-Masseteric route as well as submucosally provides reducing of pain and swelling, also required less technical skill and better patient compliance/ comfort in surgical removal of mandibular third molar extraction.

\section{ACKNOWLEDGEMENT}

These two authors contributed equally.

\section{Conflict of interest:}

The authors declare that they have no conflict of interest.

\section{Financial support:}

This research had no funding source.

\section{Key finding / highlight}

Pre-operative administration of dexamethasone offered comfort for the patients in reducing postoperative pain and swelling.

\section{REFERENCES}

1. Syed KB, Al Qahtani FH, Mohammad AH, Abdullah IM, Qahtani HS, Hameed MS. Assessment of pain, swelling and trismus following impacted third molar surgery using injection dexamethasone submucosally: A prospective, randomized, crossover clinical study. J Int Oral Health 2017;9:116-21. http://www.jioh.org/text. asp?2017/9/3/116/209058 
2. Elitsa G. Deliverska, Milena Petkova: complications after extraction of impacted third molars- literature review. Journal of IMAB - Annual Proceeding (Scientific Papers) 2016 ;22(3). https://doi.org/10.5272/jimab.2016223.1202

3. Acham S, Klampfl A, Truschnegg A, Kirmeier R, SandnerKiesling A, Jakse N, Beneficial effect of methylprednisolone after mandibular third molar surgery: a randomized, double-blind, placebo-contolled split-mouth trial. Clin Oral Invest 2013;17:1693-700. https://doi.org/10.1007/ s00784-012-0867-1

4. Au AH, Choi SW, Cheung CW, Leung YY. The efficacy and clinical safety of various analgesic combinations for post-operative pain after third molar surgery: a systematic review and meta-analysis. PLoS ONE 2015;10: e0127611. https://doi.org/10.1371/journal.pone.0127611

5. Bibi K, Mohsin F, Sidra TM, Kamran K. Effect of submucosal injection of dexamethasone on post-operative swelling and trismus following impacted mandibular third molar surgery. Pakistan Oral \& Dental Journal 2017;37:231-234.

6. Schultze-Mosgau S, Schmelzeisen R, Frölich JC, Schmele H, Heargraves KM. Use of ibuprofen and methylprednisolone for the prevention of pain and swelling after removal of impacted third molars. J Oral Maxillofac Surg. 1995;53:28. https://doi.org/10.1016/0278-2391(95)90486-7.

7. Arakeri G, Rai KK, Shivakumar HR, Jayade B. A randomized clinical trial to compare the efficacy of submucosal aprotinin injection and intravenous dexamethasone in reducing pain and swelling after third molar surgery: A prospective study. J Maxillofac Oral Surg 2013;12:739. https://doi.org/10.1007/s12663-012-0364-8

8. Grossi GB, Maiorana C, Garramone RA, Borgonovo A, Beretta M, Farronato D, Santoro F. Effect of submucosal injection of dexamethasone on postoperative discomfort after third molar surgery: a prospective study. J Oral Maxillofac Surg 2007; 65:2218-26. https://doi.org/10.1016/j. joms.2006.11.036

9. Nithin M, Ahkin J, Anju S, Rino R, Annie V. Postoperative evaluation, after surgical removal of mandibular third molar, with and without local administration of injection dexamethasone $8 \mathrm{mg}$ : A comparative study. Int journal of preventive and clinical dental research. 2019; 6:35-38 https://doi.org/10.4103/INPC.INPC_30_19
10. Nikhil S, Akshay S, Praveen K, Diljith R, Vivek B, Saurabh G. Comparison of Preemptive Effect of Dexamethasone and Methylprednisolone After Third Molar Surgery: A Split- Mouth Randomized Triple-Blind Clinical Trial. J. Maxillofac. Oral Surg. 2020 https://doi.org/10.1007/ s12663-020-01346-7

11. Daniella N, Victor C, Lesly C, Luis G. Comparison of the antiinflammatory effectiveness of dexamethasone as pre-surgical and post-surgical therapy in mandibular third molar surgery: A randomized clinical trial. J Oral Res 2019;8:463-470. https://doi.org/10.17126/joralres.2019.068

12. Graziani F, D'Aiuto F, Arduino PG, Tonelli M, Gabriele M. Perioperative dexamethasone reduces post-surgical sequelae of wisdom tooth removal. a split-mouth randomized doublemasked clinical trial. Int J Oral Maxillofac Surg 2006;35:241246. https://doi.org/10.1016/j.ijom.2005.07.010

13. Herrera-Briones FJ, Prados Sanchez E, Reyes Botella C, Vallecillo Capilla M. Update on the use of corticosteroids in third molar surgery: systematic review of the literature. Oral surgery, Oral medicine, Oral pathology and Oral radiology 2013;116:342-51. https://doi.org/10.1016/j.0ooo.2012.02.027

14. Warraich R, Faisal M, Rana M, Shaheen A, Gellrich NC, Rana M. Evaluation of postoperative discomfort following third molar surgery using submucosal dexamethasone - a randomized observer blind prospective study. Oral surgery, Oral medicine, Oral pathology and Oral radiology 2013;116:1622. https://doi.org/10.1016/j.oooo.2012.12.007

15. Ehsan A, Bukhari SGA, Ashar AM, Junaid M. Effects of pre-operative submucosal dexamethasone injection on the postoperative swelling and trismus following surgical extraction of mandibular third molar. J Coll Physicians Surg Pak 2014;24:489-92.

16. Ehsan S, Milad P. Comparison of the Effects of Dexamethasone Administration on Postoperative Sequelae Before and After "Third Molar" Extraction Surgeries. Endocrine, Metabolic \& Immune Disorders - Drug Targets 2020 ;20. https://doi.org/10.2174/1871530319666190722120405

17. Chugh A, Singh S, Mittal Y, Chugh V. Submucosal injection of dexamethasone and methylprednisolone for the control of postoperative sequelae after third molar surgery: randomized controlled trial. Int jour of oral and maxillof surg 2017;47:228-233. https://doi.org/10.1016/j.jjom.2017.07.009 